\title{
Studying Poverty in Economics - The Work of the 2019 Nobel Prize Laureates*
}

\author{
Klára Major
}

In 2019, the Nobel Prize in Economic Sciences was awarded jointly to Abhijit Banerjee, Esther Duflo and Michael Kremer "for their experimental approach to alleviating global poverty". Their work gave rise to the transformation of development economics both in terms of approach and methodology: the effect of the development programmes aimed at reducing poverty is now typically measured by randomised controlled trials, enabling researchers to reveal causal effects. Throughout their studies, the authors relentlessly seek the drivers of human behaviour with a view to enabling the design of effective development programmes based on a deeper understanding of the nutrition, health, education, finances, etc. of the poor.

Journal of Economic Literature (JEL) codes: B31, B41, 012, C93

Keywords: poverty, development economics, Nobel Prize in Economic Sciences

\section{Foreword}

In 2019, the Nobel Prize in Economic Sciences ${ }^{1}$ was awarded jointly to Abhijit Banerjee, Esther Duflo and Michael Kremer "for their experimental approach to alleviating global poverty". Traditionally, the Noble Prize goes to economists who introduce a novel approach to scientific thinking with a sizable impact on contemporary researchers, often receiving this prestigious award as a culmination of their scientific career. How should we take measure of the 2019 Laureates? How significant is their contribution to economic sciences as a whole? Can we deem their nomination this year a surprising choice of the Committee?

To begin with, let us look at the numbers and a few dry facts. It is a fact that among the 84 Laureates in Economic Sciences who have received the prize since 1969, Esther Duflo is only the second female researcher. It is another fact that, at 47, she is also the youngest Laureate among the winners of the Nobel Prize in Economic Sciences. But she is not the only one who stands out from the crowd for her youth:

* The papers in this issue contain the views of the authors which are not necessarily the same as the official views of the Magyar Nemzeti Bank.

Klára Major is an Institute Leader Associate Professor at Corvinus University of Budapest.

E-mail: major@uni-corvinus.hu

The Hungarian manuscript was received on 29 January 2020.

DOI: http://doi.org/10.33893/FER.19.1.119131

${ }^{1}$ Specific title: Prize in Economic Sciences in Memory of Alfred Nobel. 
there were only four Laureates younger than Michael Kremer and twelve younger than Abhijit Banerjee in the history of the Prize. And as a team, at the average age of 58 , the three of them were 5 years younger on average upon being awarded the Prize than the "second youngest team" - Robert C. Merton and Myron S. Scholes. Contrary to the practice of previous years, this year's overall team of Laureates is the youngest so far: while being recognised may seem surprising at this early age, it is by no means an accident.

This is evidenced by the numbers themselves (Table 1). The science-metrics of the three Laureates indicate significant scientific performance both in terms of the number of papers and volumes and the number of citations. The three Laureates achieved an impressive position in the worldwide ranking of the international economic researcher community based on aggregate scientific performance: Banerjee ranks 73rd, while Duflo and Kremer rank 97th and 746th, respectively. Accordingly, all three economists are in the top 1.5 per cent, although the scores of Duflo and Banerjee put them in the top 1 thousandth. ${ }^{2}$

\section{Table 1}

Science-metrics of the $\mathbf{2 0 1 9}$ Nobel Prize Laureates in Economic Sciences

\begin{tabular}{l|c|c|c} 
& Abhijit Banerjee & Esther Duflo & Michael Kremer \\
\hline Publications & 272 & 219 & 130 \\
\hline Independent citations & 8,538 & 9,390 & 3,033 \\
\hline Hirsch-index & 44 & 42 & 28 \\
\hline Source: ideas.repec.org
\end{tabular}

For now, however, let us continue with the facts. It is yet another fact that in this day and age - the age of artificial intelligence, space research and digitisation - about five million children under the age of 5 still die of diseases that could have been prevented or cured with inexpensive treatments. Moreover, in 201510 per cent of the world's total population - more than 700 million people - lived in extreme poverty. This is at a time when in most developed countries health problems are far more related to obesity than to the lack of food. There is an endless list of devastating poverty statistics and quasi facts; indeed, it is impossible not to be confronted by these facts unless we consciously try to ignore them.

Poverty as a phenomenon and a problem is nothing new. The history of mankind can be viewed as breaking out of the shackles of poverty; from a historical perspective, the percentage of those living in relative welfare increases continuously. Similarly, focusing on past decades it becomes evident that the percentage of those living

${ }^{2}$ Based on the science-metrics data of the ideas.repec.org website. The list of the top 5 per cent contains 2,880 names.

${ }^{3}$ The Hirsch-index or h-index - in short - is an indicator of scientific effectiveness; the higher its value, the greater the researcher's impact, see in more detail in Hirsch (2005). 
under the poverty threshold has steadily declined (Figure 1), falling to around one quarter of the value recorded in 1981. While the indicators expressed as population ratios show significant improvement, absolute numbers appear to improve at a slower rate: between 1981 and 2015, the number of those living below the poverty threshold dropped to 734 million from 1.9 billion; in other words, in three and a half decades it merely halved. This is a meagre result in view of the fact that global GDP grew by 250 per cent over the past three decades (since 1990), and even GDP per capita rose by 77 per cent. We might add to the list of stunning quantitative facts that those living under the poverty line -10 per cent of the population - subsist on incomes that account for an infinitesimal 0.5 per cent of global annual income.

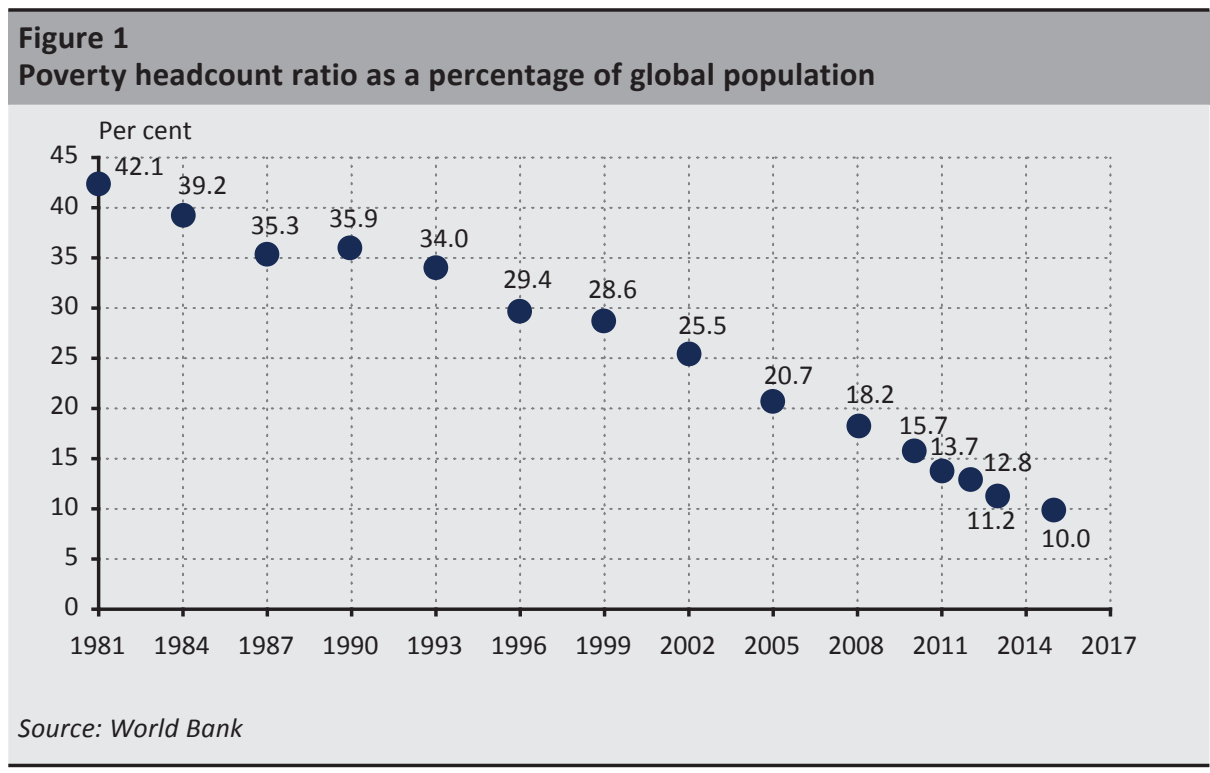

Banerjee, Duflo and Kremer made a contribution to dissecting the issue of poverty and fighting poverty in such a way that they radically broke with other contemporary approaches. Rooted in growth theory, the standard approach to development economics examines the issues of economic growth and convergence essentially at the level of and with the tools of macroeconomics. An excellent overview of this approach is, for example, Debraj Ray's textbook entitled Development Economics, published in 1998, while the historical background of the approach is presented in Thorbecke (2019). The macro approach to development economics identifies poverty with the slow growth of GDP and income and accordingly, it takes account of individual factors required for growth, concentrating primarily on the accumulation of production and human capital. The fight against poverty, in turn, is mainly embodied in aid programmes that are aimed at accelerating the accumulation of scarce physical and human capital elements in poor countries, essentially by way of aid. The deficiencies of this approach are convincingly 
highlighted in Abhijit Banerjee and Esther Duflo (2005), in Chapter 7 of the first issue of the "Handbook of Economic Growth".

Regarding the work of Banerjee, Duflo and Kremer - the three economists who received the 2019 Noble Prize - the Nobel Committee highlighted the following: ${ }^{4}$ the new experiment-based approach of the three Laureates has transformed development economics. Their approach is founded on microeconomics, and the authors rely on microeconomic data to identify and measure the impact of development programmes aimed at fighting poverty. The authors have changed research methods and approaches fundamentally in an effort to identify those aid programmes that truly improve our ability to fight poverty in practice.

1. In the mid-1990s, the Laureates conducted numerous controlled, randomised trials in Kenya to measure the impact of education. Their research findings significantly improved our understanding of how aid programmes can contribute to the accumulation of human capital.

2. They have also conducted numerous, similar research programmes in emerging countries, amassing an extraordinary amount of empirical facts and information in the process. Their regular, systematised publication of this information has transformed (public) thinking.

3. They enhanced their experimental research methods and attempted to assess whether the results of their experiments could be generalised (i.e. the issue of external validation).

In the following, we select and discuss a few important elements from the list above. Having said that, their results are not discussed comprehensively here; we merely point out the methodology applied by the authors and the significance thereof, and summarise a few of their results. We sincerely hope that by doing so we will raise the interest of Readers yet unfamiliar with the work of the Laureates as indeed, their achievements and results are not only important and useful but also very interesting, and their presentation is nothing short of brilliant.

\section{Controlled randomised trials}

Fighting poverty needs answers to such questions as the impact of education on productivity, or how the number of students in a classroom affects the educational attainment of the students. We need to explore causal relationships to answer these questions, and in order to do so, we should be able to answer such hypothetical questions as "how would the students' academic performance have changed if they had not participated in the programme"? The latter scenario

\footnotetext{
${ }^{4}$ See The Royal Swedish Academy of Sciences (2019).
} 
is non-existent, given that a person either participated in the programme or not and accordingly, only one side of the comparison is available for each individual person. Observing the same person over time and comparing his status before versus after the programme is usually unsuitable for answering this question because typically, numerous other factors have also changed in the meantime and thus, based on the changes over time, the impact of the programme cannot be distinguished from the impact of other changes.

The solution lies in control groups: control groups consist of persons who did not participate in the programme, and had they participated, their results would have been similar to those of the actual participants. As such, by way of a properly selected control group we can estimate the general impact of the programme on the treatment group, but we still cannot identify the programmes' effect on individual participants. The greatest challenge, however, is the fact that the participants of most development programmes and those not participating in the programme are typically not similar to each other in respect of the expected impact of the programme; therefore, the comparison does not make sense. For instance, if participation in the programme is organised on a voluntary basis, the level of motivation of the participants is not the same as that of non-participants. The resulting distortion is referred to as selection bias. It may arise not only from the voluntary nature of participation in the programme; this phenomenon can be observed in numerous other cases as well, for example, where participation in a programme is conditional upon some criterion such as a pre-specified income level above which a person may not participate. In such a case persons with other income levels are not suitable to be part of the control group. This also means that if all members of a target group participate in the programme, there are no subjects who would be suitable to comprise a control group. In this case, we cannot measure the impact of the programme.

Randomised controlled trials are conducted to strip out the selection bias, in the course of which in order to measure the impact of the intervention programme, a part of the target population is selected and each individual in the group is randomly assigned to the treatment group or to the control group. The treatment group participates in the programme, while the control group does not. The impact of the programme is derived from a comparison of the average dependent variables of the two groups. In a development economics context, further procedures often need to be applied in order to exclude the selection effect. Duflo et al. (2006) provide an excellent summary of these procedures.

Another significant advantage of randomised controlled trials over other programme design methods is their ability to enable researchers to measure the impact of the programme; in other words, they explore causal linkages. On an empirical basis, the definition of causality is by no means a trivial task; it is easy 
to detect obviously unrelated time series that exhibit (ostensible) covariance. ${ }^{5} \mathrm{An}$ empirical data analysis typically explores correlations, which merely means, in and of itself, that two time series move together; for example, they take higher or lower values in tandem. But how should we interpret this phenomenon? There are at least three - but often more - possible interpretations: it is possible that $X$ causes $Y$ or vice versa, but it is also possible that a third, $Z$ phenomenon causes both $\mathrm{X}$ and $\mathrm{Y}$. It often happens during time series comparisons that unrelated phenomena appear "connectible" merely because both increase or decrease over time. Determining causality is critical for researchers seeking to understand the effect or the significance of individual programmes, and virtually the only possible way to do so today is through randomised controlled trials.

Obviously, this research method is not new; in the second half of the 20th century it became the standard method of pharmaceutical research in the clinical trial phase, for the purposes of measuring the effect of pharmaceutical products. There are also a number of early examples for their use in economics ${ }^{6}$ as well; however, the application of randomised controlled trials became a standard approach mainly in the 1990s both in the studies of the three Laureates and through their example, in the work of others. Duflo and Banerjee address methodological issues in numerous studies (e.g. Banerjee et al. 2010a; Duflo et al. 2006; Banerjee et al. 2017). Essentially, the application of randomised controlled trials enabled researchers to answer previously unanswerable questions.

\section{Exploring causal effect: the drivers of human behaviour}

In order to explore causal effects, it is fundamentally important to understand the drivers of human decisions; i.e. to understand the way in which incentives, constraints and information influence human decisions. For example, the population of emerging countries is exposed to numerous health risks - such as malaria or (viral) gastroenteritis - that can be prevented or cured with relatively inexpensive treatments. Malaria vaccine costs far less than the extra income that could be realised by preventing the disease. Similarly, the cost of the chlorine required for disinfecting drinking water is only a fraction of the costs of the disease or, for that matter, the complications thereof. Why is it, then, that the use of vaccines, anti-malaria nets, or chlorine for water treatment is often neglected in emerging countries? A lay observer would probably conclude that health is not the first priority of the people living in these countries; consequently, they fail to do something about preserving it. However, interview-based qualitative studies

\footnotetext{
${ }^{5}$ The literature refers to this phenomenon as "spurious regression" - see, for example, Greene (2012), Chapter 21.2.2.

${ }^{6}$ For testing the effects of negative taxation, see, for example, Hausman - Wise (1985), or for measuring the welfare effects of social programmes in the 1980s and 1990s, the study of Manski-Garfinkel (1992).
} 
all found that the people of these countries are in fact fairly concerned about their health and spend a great deal of money for these purposes. What is it, then, that makes such spending so ineffective? In their science education book, Abhijit Banerjee and Esther Duflo (2011) demonstrate, in the succinct and tenacious manner of an investigative journalist, how the lack of reliable information, low education and insufficient knowledge can repeatedly become a source of bad decisions.

The persistence of poverty and the fact that entire generations are permanently stuck in such conditions suggest that the poor are trapped in poverty with no real way out. The life of the poor involves numerous trap situations. In addition to the health problem mentioned above, they are found in almost all areas of life, including nutrition, education decisions and finances. It appears obvious that poor nutrition may itself create a poverty trap: malnutrition prevents individuals from being able to keep step in the workplace and losing a job, in turn, makes it even more difficult - through the loss of income - for a person to put food on the table. Is this seemingly logical train of though a realistic explanation for the poverty trap? On closer look, data reveal that the picture is far more complex than that. On the one hand, the wages of better nourished employees will not necessarily be higher if the employer cannot make a distinction between a properly fed and a malnourished employee. It has been observed, for example, that physical workers tend to consume more food on days when they earn efficiency wages than on any other days. On the other hand, nutrition habits are largely influenced by ingrained habits and beliefs and are therefore fairly resistant to changes especially when a stranger shows up to offer novel reforms. In addition to all this, an empirical analysis of eating habits found that, based on the calorie content of the food consumed, most poor people are not malnourished: even if there is a nutrition issue, it has far more to do with the quality, rather than the quantity, of the food consumed. The lack of micronutrients might be a less-documented but more probable explanation for children's nutrition-related developmental delays. Insufficient iodine or iron intake restrains children's cognitive and physical development to such an extent that its impact is perceivable even in adult-age wages. For more detail, see, for example, the studies by Banerjee et al. (2010b), and Banerjee et al. (2010c).

Exploring the drivers of human behaviour is the central focus of their research. In the science education work referred to above, the authors present an extensive discussion on whether we are wrong in trying to apply the model of rational behaviour assumed by microeconomics to understand the decisions of

\footnotetext{
${ }^{7}$ Banerjee - Duflo: Poor Economics: A Radical Rethinking of the Way to Fight Global Poverty, published by Public Affairs, New York, 2011. In 2016 it was also published in Hungarian under the title "A szegények gazdálkodása" by Balassi Kiadó.
} 
the poor. Can it be a rational behaviour not to use the bed nets available free of charge for protection? How can we explain the observation that not all children complete primary education but oftentimes, the family spends all its resources on schooling one child only? Why do families use low-quality, expensive but ineffective remedies? Their research generally point out that the drivers of human behaviour among the poor are not so different from what we would expect based on our microeconomics studies: school teachers are clearly responsive to financial incentives (Duflo et al. 2012) but at the same time, more (better) textbooks or more time (days) spent at school do not lead to better performance at school, whereas an improvement in the quality of education does. (Banerjee et al. 2007; Duflo et al. 2011; Banerjee et al. 2016; Duflo et al. 2015; Duflo-Hanna 2005).

\section{Macro level conclusions "from the bottom up"}

Esther Duflo and Abhijit Banerjee summarised the results of their decades-long research in a truly enjoyable work - the science education monograph entitled "Poor Economics". ${ }^{8}$ This book alone provides a comprehensive insight into the authors' work. The book was also highlighted in the press release on awarding The Prize in Economic Sciences 2019 as it is the summary of the results of years of research, in which the authors demonstrate - both from a micro and a macroeconomic perspective - why so many well-intentioned aid programmes fail as a result of ignoring the incentives and constraints of individual behaviour.

In any discussion on economic growth or economic development, the significance of the institutional system is an unavoidable issue. Numerous studies have emphasised in recent years the enormous extent to which the institutional system determines the welfare of a nation over the long term. For example, Acemoglu and Robinson (2005) argue that a country has no chance to develop - for example, it cannot improve the enforceability of ownership rights or clamp down on corruption - if its political institutional system is outdated. An institutional system conducive to economic growth can be best described as one where a person's advancement is more likely to be influenced by individual talent than social relations. Ultimately, the institutions wield an influence on economic incentives, such as decisions related to further education, investments in innovation, the application of novel technologies, etc. In addition, political institutions also affect the extent to which the people can control politicians. When economists refer to the quality of institutions, they often choose an extremely high level of abstraction, discussing such institutions as democracy, division of power, the enforceability of ownership rights, or restricted voting rights. Economic institutions conducive to growth encourage people to invest, study, accumulate or invent new technologies

\footnotetext{
${ }^{8}$ Banerjee - Duflo (2011)
} 
- in other words, they promote activities that are important sources of economic growth and development. By contrast, institutions encouraging rent-seeking achieve just the opposite effect. These are the institutions that, instead of inciting to invest, learn or accumulate, encourage the individual to forge ahead - through relations with social or political leaders or monopolistic positions - at the expense of others. Institutions conducive to growth ultimately restrict political leaders from putting personal interests above all by forcing them to base their decisions on public interest.

Studies devoted to the role of institutions in economic growth typically confirm the findings regarding the direction of the linkages (while the way in which the quality of the institutional system can be measured is widely debated). It is still an open question, however, as to which factors can prompt a change over what horizon. Are countries condemned to being trapped in poverty and destitution forever if they inherited a "bad institutional system" due to their historical legacy? In this important and extensive debate, the empirical studies of Duflo and Banerjee contribute to expanding our knowledge by pointing out new directions in thinking. As they put it: "Acemoglu and Robinson's pessimism comes in part from the fact that we rarely see successful drastic regime change from authoritarian and corrupt to well-functioning democracy. The first thing the view from below allows us to see is that it is not always necessary to fundamentally change institutions to improve accountability and reduce corruption.

Although wholesale democratic reforms are few and far between, there are many instances where democracy has been introduced, to a limited extent and at the local level, within an authoritarian regime."

Their papers show numerous examples in this regard. Just to mention a single example: in Uganda, where schools are subsidised on a per capita basis, a survey conducted in 1996 asked a simple question: what percentage of the subsidies is actually received by the schools from the funds allocated by the Ministry? Both schools and Ministry officials were interviewed with the stunning result of only 13 per cent; the rest of the money ended up padding the pockets of various officials. Of the numerous important lessons offered by the story, we would like to highlight its outcome. The publication of the findings prompted a heated discussion in Uganda; so much so that the Ministry changed its practice and published in national papers the specific amounts allocated to each individual school. When the survey was repeated in 2001, it was found that this time around 80 per cent of the funds had actually reached the schools. This exercise (which is only one example of the countless similar stories presented in the authors' studies) proved to be very enlightening. On the one hand, if education is an important source

\footnotetext{
${ }^{9}$ Banerjee - Duflo (2011), p. 226.
} 
of development, increasing the funding of schools may contribute to economic growth. But if the funding does not even reach its destination, it cannot be expected to have such an effect. On the other hand, when discussing the role of institutions, we do not necessarily need to grapple with difficult issues; oftentimes accountability and transparency are enough to improve the efficiency of the system. In the words of the Laureates, "little changes" may have a surprisingly big impact; therefore, with respect to economic growth and the fight against poverty, far more attention should be given to details than to "big ideas" in order to ensure the uninterrupted continuation of little changes.

Having said that, we would not like to leave the Reader with the impression that the fiercest debates of Duflo, Banerjee or Kremer are aimed at the abovementioned scientific approach; i.e. that Acemoglu and Robinson are the authors' counterpole. On the contrary: the latter achieved similarly groundbreaking results in their empirical research on the role of institutions in economic development and growth than the 2019 Laureates. Economic or political institutions, however, are a fairly abstract concept, and the questions of how they should be measured and which abstraction level should be applied in individual analyses are often debated in the course of various surveys. In the works of Duflo, Banerjee and Kremer, however, institutions are often presented - as shown in the example above - in a very specific manner, enabling the authors to give much deeper insight into the issue for the purposes of the still ongoing scientific debate.

The authors clearly oppose the ("traditional") approach that attempts to address the poverty issue in general terms without focusing on such specific details as the micro nutrient content of food intake, fighting malaria, etc., and focuses most scientific debates on whether aid (generally) offers a way out of poverty or just the contrary, conserves the poverty trap. They also debate the approach of Jeffrey Sachs who argues that adverse climate factors are the major cause for poverty in the countries involved or, for example, that of William Easterly, who claims that aid "does more bad than good. It prevents people from searching for their own solutions, while corrupting and undermining local institutions and creating a selfperpetuating lobby of aid agencies." ${ }^{10}$ What is wrong with this approach? It is the question itself. The right question is not about whether aid is good or bad. This is far too generalised; effectiveness is in the details. As the authors put it:

"Whom should we believe? Those who tell us that aid can solve the problem? Or those who say that it makes things worse? The debate cannot be solved in the abstract: we need evidence. But unfortunately, the kind of data usually used to answer the big questions does not inspire confidence. [...] But if there is really no evidence for or against aid, what are we supposed to do - give up on the poor?

\footnotetext{
${ }^{10}$ Banerjee - Duflo (2011), p. 17.
} 
Fortunately, we don't need to be quite so defeatist. There are in fact answers. [...] The main disagreement shows up when we turn to the question, 'Do we know of effective ways to help the poor?'. [...] I(i)t is really helpful to think in terms of concrete problems which can have specific answers [...]."11

\section{Epilogue}

How significant, then is the work of the Laureates? Is it surprising that economists researching poverty were awarded this prestigious prize? Looking at the Laureates of previous years it appears that poverty research, healthcare, education - in general, the other branches of "public administration" - receive this significant recognition less often than other branches of science, such as macroeconomics. ${ }^{12}$ Recently, this area has been given greater recognition (as suggested by the nomination of Angus Deaton). We wish to carry this thought somewhat further. In our view, this is not merely about increased professional attention but can be rather attributed to the fact that applying the toolkit of microeconomics, the Laureates have conquered new areas, making them part of economics.

This essay was intended to be a commendation: our goal was not merely to provide an overview of the work of the economists receiving the Nobel Prize in 2019. Our primary goal was to demonstrate their significance. Their scientific work covers numerous aspects of the life of the poor; it is virtually impossible to enumerate all of their accomplishments and present them in detail; however, their novelty and effectiveness - in our opinion - point far beyond the multitude of results. The authors' work has transformed development economics; it is owing to them that we now pose the questions in a different way. They also set new standards in respect of methodology. We are convinced that the 2019 Noble Prize in Economic Sciences could not have been awarded to more deserving candidates.

\section{References}

Acemoglu, D. - Robinson, J. (2005): Economic Origins of Dictatorship and Democracy. New York, Cambridge University Press. https://doi.org/10.1017/СВ09780511510809

Banerjee, A.V. - Cole, S. - Duflo, E. - Linden, L. (2007): Remedying Education: Evidence from Two Randomized Experiments in India. The Quarterly Journal of Economics, 122(3): 1235-1264. https://doi.org/10.1162/qjec.122.3.1235

\footnotetext{
${ }^{11}$ Banerjee - Duflo (2011), pp. 18-20.

12 Thanks are due to the anonymous proofreaders for their valuable ideas and thoughts on the manuscript. Even this observation was borrowed from them.
} 
Banerjee, A.V. - Duflo, E. (2005): Growth theory through the lens of development economics. In: Durlauf, S. - Aghion, P. (eds): Handbook of Economic Growth, vol. 1A. Amsterdam: North Holland, Elsevier, pp. 473-552. https://doi.org/10.1016/S1574-0684(05)01007-5

Banerjee, A.V. - Duflo, E. (2011): Poor Economics: A Radical Rethinking of the Way to Fight Global Poverty. Public Affairs.

Banerjee, A.V. - Banerji, R. - Duflo, E. - Glennerster, R. - Khemani, S. (2010a): Pitfalls of Participatory Programs: Evidence from a Randomized Evaluation in Education in India. American Economic Journal: Economic Policy, 2(1): 1-30. https://doi.org/10.1257/pol.2.1.1

Banerjee, A.V. - Duflo, E. - Glennerster, R. (2010b): Is Decentralized Iron Fortification a Feasible Option to Fight Anemia Among the Poorest? In: Wise, D. (ed): Explorations in the Economics of Aging. Chicago, University of Chicago Press, Chapter 10.

Banerjee, A.V. - Duflo, E. - Glennerster, R. - Kothari, D. (2010c): Improving Immunisation Coverage in Rural India: Clustered Randomised Controlled Immunisation Campaigns With and Without Incentives. British Medical Journal, 340:c2220. https://doi.org/10.1136/bmj. c2220

Banerjee, A.V. - Banerji, R. - Berry, J. - Duflo, E. - Kannan, H. - Mukherji, S. - Shotland, M. Walton, M.: (2016): Mainstreaming an Effective Intervention: Evidence from Randomized Evaluations of "Teaching at the Right Level" in India. NBER Working Papers 22746, National Bureau of Economic Research, Inc. https://doi.org/10.3386/w22746

Banerjee, A.V. - Banerji, R. - Berry, J. - Duflo, E. - Kannan, H. - Mukerji, S. - Shotland, M. - Walton, M. (2017): From Proof of Concept to Scalable Policies: Challenges and Solutions, with an Application. Journal of Economic Perspectives, 31(4): 73-102. https:// doi.org/10.1257/jep.31.4.73

Duflo, E. - Glennerster, R. - Kremer, M. (2006): Using Randomization in Development Economics Research: A Toolkit. NBER Technical Working Papers 0333, National Bureau of Economic Research, Inc. https://doi.org/10.3386/t0333

Duflo, E. - Dupas, P. - Kremer, M. (2011): Peer Effects, Teacher Incentives, and the Impact of Tracking: Evidence from a Randomized Evaluation in Kenya. American Economic Review, 101(5): 1739-1774. https://doi.org/10.1257/aer.101.5.1739

Duflo, E. - Dupas, P. - Kremer, M. (2015): School governance, teacher incentives, and pupilteacher ratios: Experimental evidence from Kenyan primary schools. Journal of Public Economics, 123(C): 92-110. https://doi.org/10.1016/j.jpubeco.2014.11.008

Duflo, E. - Hanna, R. (2005): Monitoring Works: Getting Teachers to Come to School. NBER Working Papers 11880, National Bureau of Economic Research, Inc. https://doi. org/10.3386/w11880 
Duflo, E. - Hanna, R. - Ryan, S.P. (2012): Incentives Work: Getting Teachers to Come to School. American Economic Review, 102(4): 1241-1278. https://doi.org/10.1257/aer.102.4.1241

Greene, W.H. (2012): Econometric Analysis. Prentice Hall, New York, 7th edition.

Hausman, J.A. - Wise, D.A. (1985): Social Experimentation. Chicago, University of Chicago Press. https://doi.org/10.7208/chicago/9780226319421.001.0001

Hirsch, J.E. (2005): An index to quantify an individual's scientific research output. Proceedings of the National Academy of Sciences of the United States of America, 102(46): 1656916572. https://doi.org/10.1073/pnas.0507655102

Manski, C.F. - Garfinkel, I. (1992): Evaluating Welfare and Training Programs. Cambridge, Harvard University Press.

Ray, D. (1998): Development Economics. Princeton University Press.

The Royal Swedish Academy of Sciences (2019): Understanding development and poverty alleviation. Scientific background on the Sveriges Riksbank Prize in Economic Sciences in Memory of Alfred Nobel 2019, The Committee for the Prize in Economic Sciences in Memory of Alfred Nobel. https://www.nobelprize.org/uploads/2019/10/advancedeconomicsciencesprize2019.pdf

Thorbecke, E. (2019): The History end Evolution of the Development Doctrine, 19502017. In: Nissanke, M. - Ocampo, J.A. (eds): The Palgrave Handbook of Development Economics: Critical Reflections on Globalisation and Development., Springer, pp. 61-108. https://doi.org/10.1007/978-3-030-14000-7_3 